DOI:

УДК 517.4:534.6

Ю.М. Головко, канд. фіз.-мат. наук, доцент, holovko.yu.m@nmu.one

НТУ «Дніпровська політехніка», кафедра вищої математики, м. Дніпро

\title{
МАТЕМАТИЧНА МОДЕЛЬ МЕХАНІЧНОЇ СИСТЕМИ ПРИЙМАЧА СЕЙСМОАКУСТИЧНИХ КОЛИВАНЬ
}

При дослідженнях сейсмоакустичних коливань відзначається істотний вплив властивостей трунту в точиі розміщення сейсмоприймача. У даній статті розглядається динаміка сейсмоприймача, що враховує умови на контакті з трунтом. Модель описується системою звичайних диференціальних рівнянь. Для вирішення системи використано перетворення Лапласа. Знайдені передаточна функиія, частотна характеристика, імпульсна перехідна функиія. Отримано кінщеві вирази для вимірюваних кінематичних параметрів інериійної маси геофону при різних впливах та початкових умовах. Наведено результати розрахунків для сейсмоприймача дорезонансного типу.

Ключові слова: диференціальні рівняння; операційне числення; сейсмоакустика; геофон.

The effect of the soil properties is significantly to the seismic receiver-ground coupling that is noted by the study of seismoacoustic oscillations. In this paper are considered the seismic receiver dynamics in the conditions at the coupling between seismic receiver and the soil. The model is described by a system of ordinary differential equations. The Laplace transformation is used to solve the problem. The transfer function, frequency response, impulse transient function are found. The final expressions are obtained for the measured parameters of the inertial mass of geophone (velocity, acceleration) at various types of influences and initial conditions. The results of calculations for preresonance seismic receiver are presented.

Keywords: differential equations; operational calculus; seismic acoustics; geophone.

\section{Постановка проблеми}

Серед геофізичних методів сейсмоакустика має найбільш широку область застосування. Залежно від довжин зареєстрованих пружних хвиль (сейсмічних, акустичних, ультразвукових) методи сейсмоакустики дозволяють отримувати інформацію щодо фізико-механічних властивостей грунтів в зонах істотно різного масштабу: від геосфер Землі до біля поверхневого шару оголення гірської породи.

Незалежно від галузі використання обов'язковим елементом сейсмоакустичних систем $\epsilon$ сейсмоприймач (геофон) - віброметр інерційного типу, що призначений для перетворення механічних коливань грунту в електричний сигнал. Можна виділити дві підсистеми геофонів. Механічна підсистема забезпечує перетворення кінематичної характеристики сейсмоприймача як цілого в відносну кінематичну характеристику інерційної системи приладу. Електрична підсистема перетворює останню в пропорційний електричний сигнал. Для реєстрації коливань в акустичному діапазоні використовуються електродинамічні і п'єзоелектричні сейсмоприймачі. У електродинамічному сейсмоприймачі електричний сигнал пропорційний швидкості переміщення інерційної маси, при цьому коректно реєструються коливання корпусу, що перевищують власну частоту інерційної маси на пружності ії зв'язку з корпусом. У п'єзоелектричному сейсмоприймачі електричний сигнал пропорційний відносному зміщенню інерційної маси щодо корпусу, номінальний частотний інтервал коливань корпусу не повинен перевищувати третини власної частоти інерційної системи приладу. При виготовленні сейсмоприймачів параметри як електричної, так і власної механічної підсистем цілком однозначно визначаються і контролюються. Однак, метою вимірювань $\epsilon$ визначення параметрів коливань не корпусу, а грунту на (в) якому він встановлений. I якщо робота електричної підсистеми практично не залежить від умов використання геофонів, то робота механічної підсистеми істотно змінюється в залежності від характеристик грунту в «точці» установки приладу. 
Моделювання механічної підсистеми сейсмоприймача, що враховує зв'язок геофонів 3 грунтом, має дозволити оцінити вплив різних чинників на достовірність зареєстрованих параметрів i, можливо, коригувати одержувані експериментальні дані.

\section{Аналіз останніх досліджень та публікацій}

Із загальних міркувань з самого початку було зрозуміло, що рух геофону може не збігатися з рухом грунту [1]. Однак поки основним параметром був час приходу в точку вимірювання ( «перший вступ»), ця відмінність не мало особливого значення. Помітний вплив умов зв'язку сейсмоприймача 3 грунтом починають відзначати при більш детальному дослідженні реєстрованих сигналів. Вже при перших дослідженнях, пов'язаних 3 виділенням на сейсмограмах ділянок, що відповідають різним типам хвиль [2] а також дослідженнях, що спираються на спектральний склад реєстрованих коливань $[3,4]$, такий вплив став очевидним. Проте проблема залишається недостатньо вивченою і $є$ предметом розгляду багатьма дослідниками.

В роботі [5] на основі досліджень шести різних методів зчеплення геофону з гірськими породами при дії коливань в інтервалі частот від $2 \mathrm{~Hz}$ до $190 \mathrm{~Hz}$ встановлено, що здатність вимірювальної системи правильно сприймати зовнішні коливання істотно залежить від способу зчеплення корпусу приладу з породою. Найкращі результати отримані при використанні анкерного кріплення. При більш піддатливих умовах на контакті другий екстремум на амплітудному спектрі зміщується всередину досліджуваного інтервалу частот.

У статті [6], відзначаючи важливість контактних умов для правильної інтерпретації результатів вимірювань, запропонований метод калібрування геофонів, що вимагає тільки простих вимірювань імпедансу датчика як функції частоти. При цьому для оцінки імпедансу на контакті порода-геофон використана частотна характеристика з роботи Krohn C.E [7]. Слід зауважити, що раніше частотна характеристика для тих же умов була отримана М.С. Анциферовим [3].

В роботі [8] констатуючи, що звичайні геофони мають поганий зв'язок з поверхню грунту, розроблений і досліджений геофон з додатковими конструктивними елементами, що підвищують жорсткість контакту. Порівняльні експерименти показали, що це підвищення жорсткості призвело до значного розширення спектра сигналів.

В роботі [9] експериментально вивчається поведінка вібраторів і геофонів на твердому і м'якому грунті. Встановлено, що вібратор на м'якому грунті на додаток до гармонійних коливань виробляє також субгармонійні і ультра-субгармонійні коливання. Коли геофон знаходився на м'якому грунті дані, що реєструвалися геофоном, були спотворені. При цьому спостерігалася модуляція сигналів коливаннями геофону. Побудована авторами модель на основі [7] не змогла пояснити погіршення характеристик реєстрованого сигналу.

Наведені публікації свідчать про актуальність досліджень пов'язаних з урахуванням властивостей грунту при вимірюваннях сейсмоакустичних коливань. У більшій частині ці роботи містять результати експериментальних досліджень. Математичне моделювання обмежується зверненням до частотної характеристики, що має два очевидних екстремуми. Одночасно вказується на неадекватність розрахункових значень і необхідність уточнення моделей що застосовуються.

\section{Формулювання мети дослідження}

Побудувати математичну модель механічної системи приймача сейсмоакустичних коливань і отримати залежності, що зв'язують характеристики первинних зареєстрованих параметрів 3 параметрами зовнішнього впливу.

\section{Виклад основного матеріалу}

Прийнята розрахункова схема системи геофон-грунт показана на рис. 1 , де $M, m-$ маси корпусу та інерційного елемента; $K, A$ - коефіцієнти жорсткості та в'язкості контакту корпусгрунт; $k, \alpha$ - коефіцієнти жорсткості та в'язкості пружного елемента геофону, $x=x(t)$ - переміщення інерційного елемента щодо корпусу; $y=y(t)$ - переміщення корпусу щодо грунту; $\xi=\xi(t)$ - переміщення грунту щодо інерціальної системи відліку. 


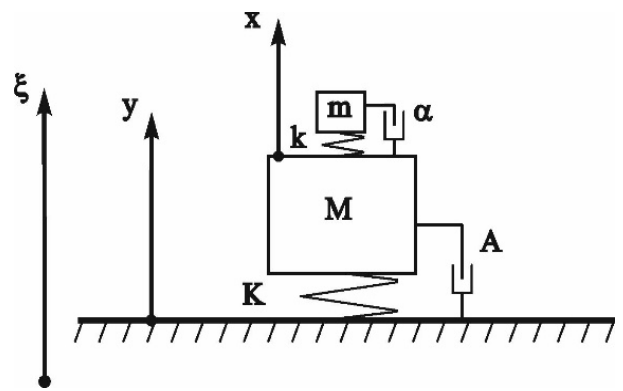

Puc. 1. Розрахункова схема геофону, що пов'язаний з грунтом

Всі переміщення можливі лише в одному напрямку і відраховуються від початкового врівноваженого стану системи. Коефіцієнт жорсткості $K$ визначається як коефіцієнт щодо похідної контактної сили по зближенню в початковому стані. Рух системи визначається функцією переміщення $\xi(t)$, що розглядається як зовнішня дія.

Дана модель передбачає також наступні допущення: корпус геофону абсолютно жорсткий; довжина корпусу $l$, швидкість поздовжніх коливань в грунті $c_{p}$ і найбільша частота $f_{m}$ гармонійної складової функції $\xi(t)$ пов'язані співвідношенням $l \cdot f_{m} \ll c_{p}$; рух геофону не впливає на $\xi(t)$; відхилення системи від врівноваженого стану малі і допускають лінеаризацію залежності сили контактної взаємодії від зближення контактуючих тіл.

Рівняння руху для корпусу і інерційної маси будуть

$$
\begin{gathered}
-M \frac{d^{2}}{d t^{2}}(y+\xi)-K y-A \frac{d y}{d t}+k x+\alpha \frac{d x}{d t}=0, \\
-m \frac{d^{2}}{d t^{2}}(y+x+\xi)-k x-\alpha \frac{d x}{d t}=0 .
\end{gathered}
$$

Використовуючи позначення

$$
\begin{gathered}
\omega_{0}^{2}=\frac{k}{m}, \quad \Omega_{0}^{2}=\frac{K}{M}, \\
W_{0}=\frac{\Omega_{0}}{\omega_{0}}, \quad \mu=\frac{m}{M}, \quad \lambda=\frac{\alpha}{2 m \omega_{0}}, \Lambda=\frac{A}{2 M \Omega_{0}}
\end{gathered}
$$

і вибираючи в якості масштабу часу $\frac{1}{\omega_{0}}$, а довжини - максимум модуля $\xi(t)$, систему (1), (2) представимо у вигляді (далі $t, x, y-$ безрозмірні величини)

$$
\begin{gathered}
\frac{d^{2} y}{d t^{2}}+2 W_{0} \Lambda \frac{d y}{d t}+W_{0}^{2} y-2 \mu \lambda \frac{d x}{d t}-\mu x=-\frac{d^{2} \xi}{d t^{2}}, \\
\frac{d^{2} y}{d t^{2}}+\frac{d^{2} x}{d t^{2}}+2 \lambda \frac{d x}{d t}+x=-\frac{d^{2} \xi}{d t^{2}} .
\end{gathered}
$$

Розв'язок буде залежати від безрозмірних комплексів з очевидною фізичною інтерпретацією: $\mathcal{M}$ - відношення маси інерційного елемента до маси корпусу (приведена маса); $\lambda, \Lambda$ коефіцієнти затухання, що характеризують розсіювання енергії на внутрішніх і зовнішніх зв'язках сейсмоприймача; $W_{0}$ - відношення частоти встановлення до номінальної частоти інерційної маси.

Будемо шукати розв'язок системи (3), (4) при початкових умовах

$$
y(0)=y_{0}, \quad y^{\prime}(0)=y_{0}^{\prime}, \quad x(0)=x_{0}, \quad x^{\prime}(0)=x_{0}^{\prime},
$$

при заданих параметрах $\mu, \lambda, \Lambda, W_{0}$ і залежності зовнішньої дії від часу $\xi(t)$.

Система (3), (4) з урахуванням (5) в зображеннях Лапласа приймає вигляд 


$$
\begin{gathered}
-(2 \mu \lambda p+\mu) X+\left(p^{2}+2 \Lambda p+W_{0}^{2}\right) Y=-F+p\left(y_{0}+2 \Lambda\right)-2 \mu \lambda x_{0}+y_{0}^{\prime} \\
\left(p^{2}+2 \lambda p+1\right) X+p^{2} Y=-F+p\left(y_{0}+x_{0}\right)+2 \lambda x_{0}+y_{0}^{\prime}+x_{0}^{\prime},
\end{gathered}
$$

де $X=X(p), Y=Y(p), F=F(p)-$ зображення функцій $x(t), y(t), \frac{d^{2} \xi}{d t^{2}}$ відповідно; $p-$ комплексна змінна.

Розв'язок системи щодо $X$

$$
X(p)=\frac{-\left(W_{0}^{2}+2 \Lambda p\right) F+x_{0} p^{3}+\left(x_{0}^{\prime}+2 b_{0} x_{0}\right) p^{2}+\left(W_{0}^{2} a_{0}+2 \Lambda a_{1}\right) p+W_{0}^{2} a_{1}}{\left(W_{0}^{2}+p^{2}+2 \Lambda p\right)\left(p^{2}+2 \lambda p+1\right)+(\mu+2 \mu \lambda p) p^{2}},
$$

де $a_{0}=x_{0}+y_{0} ; \quad a_{1}=x_{0}^{\prime}+y_{0}^{\prime}+2 \lambda x_{0} ; \quad b_{0}=\Lambda+\lambda(\mu+1)$.

Далі, нехай $\frac{d^{2} \xi}{d t^{2}}=\delta_{1}(t)$, де $\delta_{1}(t)-$ одинична імпульсна функція Дірака $\left(\delta_{1}(t)=\left\{\begin{array}{ll}\infty, & t=0, \\ 0, & t \neq 0 ;\end{array} \int_{-\infty}^{\infty} \delta_{1}(t) d t=1\right)\right.$, і вважаючи, відповідно, $F=1$, а початкові умови $\epsilon$ нульовими, з (6) отримаємо передаточну функцію $X(p)$ для реакції механічної системи геофону у вигляді зміщення $x$ на зовнішнє прискорення $\frac{d^{2} \xi}{d t^{2}}$ (вхід - прискорення, вихід - переміщення)

$$
X(p)=\frac{-\left(W_{0}^{2}+2 \Lambda p\right)}{\left(W_{0}^{2}+p^{2}+2 \Lambda p\right)\left(p^{2}+2 \lambda p+1\right)+(\mu+2 \mu \lambda p) p^{2}} .
$$

Вважаючи в (7) $p=i W$, отримаємо частотну характеристику

$$
X(W)=\frac{W_{0}^{2}+i 2 \Lambda W}{-W^{4}+S_{1} W^{2}-W_{0}^{2}+i 2 W\left(S_{2} W^{2}-S_{3}\right)},
$$

де $S_{1}=S_{1}\left(W_{0}, \mu, \Lambda, \lambda\right)=W_{0}^{2}+4 \Lambda \lambda+\mu+1 ; S_{2}=S_{2}\left(W_{0}, \mu, \Lambda, \lambda\right)=\Lambda+(\mu+1) \lambda$;

$S_{3}=S_{3}\left(W_{0}, \mu, \Lambda, \lambda\right)=\lambda W_{0}^{2}+\Lambda ; W-$ безрозмірна частота (масштаб - $\left.\omega_{0}\right)$.

Амплітудно-частотна характеристика (АЧХ) буде

$$
|X(W)|=\frac{\sqrt{W_{0}^{4}+4 \Lambda^{2} W^{2}}}{\sqrt{\left(W^{4}-S_{1} W^{2}+W_{0}^{2}\right)^{2}+4 W^{2}\left(S_{2} W^{2}-S_{3}\right)^{2}}} .
$$

Фазо-частотну характеристику (ФЧХ) можна знайти за формулою

$$
\varphi_{X}(W)=\varphi_{*}[\operatorname{Re}(X(W)), \operatorname{Im}(X(W))],
$$

де $\varphi_{*}(x, y)=2 \operatorname{arctg}\left(\frac{y}{x+\sqrt{x^{2}+y^{2}}}\right)$.

3 (8) видно, що при необмеженому зростанні жорсткості $W_{0}$ й (або) коефіцієнта затухання на контакті $\Lambda$ частотні характеристики добігають до частотних характеристик одномасової системи. Дійсно, якщо враховувати функціональні залежності щодо $S_{1}\left(W_{0}, \mu, \Lambda, \lambda\right)$, $S_{2}\left(W_{0}, \mu, \Lambda, \lambda\right)$ і $S_{3}\left(W_{0}, \mu, \Lambda, \lambda\right)$ з (12) випливає

$$
\lim _{W_{0} \rightarrow \infty} X\left(W_{0}, \mu, \Lambda, \lambda, W\right)=\lim _{\Lambda \rightarrow \infty} X\left(W_{0}, \mu, \Lambda, \lambda, W\right)=\frac{1}{W^{2}-1-2 i \lambda W} .
$$

Слід зауважити, що необмежене збільшення коефіцієнта затухання інерційної системи датчика л призводить до нульового значення частотної характеристики.

Якщо вихідний сигнал є пропорційним швидкості деформації механічної системи геофону $\frac{d x}{d t}$, а в якості вхідного сигналу розглядається швидкість $\frac{d \xi}{d t}$ (вхід - швидкість, вихід швидкість), тоді частотна характеристика $V(W)$ буде 
а АЧХ і ФЧХ відповідно

$$
V(W)=\frac{i W \cdot X(W)}{\frac{1}{i W}}=-W^{2} \cdot X(W),
$$

$$
\begin{gathered}
|V(W)|=W^{2} \cdot|X(W)| \\
\text { i } \left.\varphi_{V}(W)=\varphi^{*}[\operatorname{Re}(V(W))), \operatorname{Im}(V(W))\right]=\varphi_{X}(W)-\pi .
\end{gathered}
$$

Імпульсну перехідну функцію $h(t)$ можна знайти як зворотне перетворення передаточної функції $H(p)$. У відповідності з другою теоремою розкладання і помічаючи, що коефіцієнти многочленів чисельника і знаменника (7) $є$ дійсними числами [10]

$$
h(t)=\sum_{p_{k}} \frac{C_{H}\left(p_{k}\right)}{Z_{H}^{\prime}\left(p_{k}\right)} e^{p_{k} t}+2 \operatorname{Re} \sum_{q_{k}} \frac{C_{H}\left(q_{k}\right)}{Z_{H}^{\prime}\left(q_{k}\right)} e^{q_{k} t},
$$

де $Z_{H}(p)=\left(W_{0}^{2}+p^{2}+2 \Lambda p\right)\left(p^{2}+2 \lambda p+1\right)+(\mu+2 \mu \lambda p) p^{2}$ і $C_{H}(p)=-\left(W_{0}^{2}+2 \Lambda p\right)-$ знаменник и чисельник $H(p), p_{k}-$ усі дійсні корені $Z_{H}(p), q_{k}-$ усі комплексні корені $Z_{H}(p)$ з додатними уявними частинами.

Аналогічно, для доданків (6), що залежать від початкових умов, знаходимо функцію

$$
h_{0}(t)=\sum_{p_{k}} \frac{C_{H 0}\left(p_{k}\right)}{Z_{H}^{\prime}\left(p_{k}\right)} e^{p_{k} t}+2 \operatorname{Re} \sum_{q_{k}} \frac{C_{H 0}\left(q_{k}\right)}{Z_{H}^{\prime}\left(q_{k}\right)} e^{q_{k} t},
$$

де $C_{H 0}(p)=x_{0} p^{3}+\left(x_{0}^{\prime}+2 b_{0} x_{0}\right) p^{2}+\left(W_{0}^{2} a_{0}+2 \Lambda a_{1}\right) p+W_{0}^{2} a_{1}$.

Тепер, виходячи з розв'язку в зображеннях (6), розв'язок $x(t)$ системи (3), (4) з урахуванням початкових умов (5) при довільній функції $\frac{d^{2} \xi}{d t^{2}}=\xi^{\prime \prime}(t)$, можна надати у вигляді суми $h_{0}(t)$ і згортки функцій $h(t)$ і $\xi^{\prime \prime}(t)$

$$
x(t)=\int_{0}^{t} h(\tau) \xi^{\prime \prime}(t-\tau) d \tau+h_{0}(t) .
$$

Якщо зовнішній вплив задається у вигляді $\frac{d \xi}{d t}=\xi^{\prime}(t)$ або $\xi(t)$ відповідно

$$
\begin{gathered}
x(t)=\int_{0}^{t} h^{\prime}(\tau) \xi^{\prime}(t-\tau) d \tau-h(t) \xi^{\prime}(0)+h_{0}(t) ; \\
x(t)=\int_{0}^{t} h^{\prime \prime}(\tau) \xi(t-\tau) d \tau-h(t) \xi^{\prime}(0)-h^{\prime}(t) \xi(0)+h^{\prime}(0) \xi(t)+h_{0}(t) .
\end{gathered}
$$

Формули (12), (13) і (14) визначають деформацію механічної системи вимірювача. Якщо у якості контрольованої величини використовується не деформація, а швидкість деформації механічної системи, то, з огляду на відому формулу для похідної інтеграла з границями залежними від змінної диференціювання, з (12) можна отримати

або

$$
\begin{gathered}
\frac{d x}{d t}(t)=\int_{0}^{t} h(\tau) \xi^{\prime \prime \prime}(t-\tau) d \tau+h(\tau) \xi^{\prime \prime}(+0)+h_{0}^{\prime}(t) \\
\frac{d x}{d t}(t)=\int_{0}^{t} h^{\prime}(t-\tau) \xi^{\prime \prime}(\tau) d \tau+h_{0}^{\prime}(t) .
\end{gathered}
$$

Якщо збуджуючий вплив розглядати як швидкість $\frac{d \xi}{d t}=\xi^{\prime}(t)$, тоді бажано мати вираз, що не потребує диференціювання $\xi^{\prime}(t)$. Вираз щодо зміщення отримаємо інтегруванням (12) частинами, а вираз щодо швидкості отримаємо, використавши далі до отриманої залежності згадану формулу диференціювання інтеграла зі змінними границями 


$$
\begin{gathered}
x(t)=\int_{0}^{t} h^{\prime}(\tau) \xi^{\prime}(t-\tau) d \tau-h(t) \xi^{\prime}(+0)+h_{0}(t) \\
\frac{d x}{d t}(t)=\int_{0}^{t} h^{\prime \prime}(t-\tau) \xi^{\prime}(\tau) d \tau-h^{\prime}(t) \xi^{\prime}(+0)+h_{0}^{\prime}(t) .
\end{gathered}
$$

Формули (13-18) отримані враховуючи $h(+0)=h^{\prime}(+0)=0$.

Функції $h^{\prime}(t), h^{\prime \prime}(t), h_{0}^{\prime}(t)$, що потрібні для розрахунків за формулами $(15-18)$ і можуть бути легко знайдені з (10) та (11).

Якщо вплив є сумою детермінованої $\xi^{\prime \prime}(t)$ та незалежної випадкової $\Xi_{2}(t)$ функцій, тоді розв'язок системи (5), (6), в силу їі лінійності, також буде сумою детермінованої $x(t)$ і випадкової $X(t)$ функцій. Першу з них, $x(t)$, можна знайти за одним з наведених вище виразів. Характеристики випадкової складової $X(t)$ : математичне очікування $m_{X}(t)$, кореляційну функцію $K_{X}\left(t, t_{1}\right)$ та дисперсію $D_{X}(t)$ можна порахувати, використовуючи отриману перехідну функцію за формулами

$$
\begin{gathered}
m_{X}(t)=\int_{0}^{t} h(t-\tau) m_{\Xi_{2}}(\tau) d \tau ; \\
K_{X}\left(t, t_{1}\right)=M\left[\left(X(t)-m_{X}(t)\right)\left(X\left(t_{1}\right)-m_{X}(t)\right)\right]=\int_{0}^{t} \int_{0}^{t_{1}} h(t-\tau) h\left(t_{1}-\tau_{1}\right) K_{\Xi_{2}}\left(\tau, \tau_{1}\right) d \tau_{1} d \tau ; \\
D_{X}(t)=K_{X}(t, t)=\int_{0}^{t} \int_{0}^{t} h(t-\tau) h\left(t-\tau_{1}\right) K_{\Xi_{2}}\left(\tau, \tau_{1}\right) d \tau_{1} d \tau,
\end{gathered}
$$

де $m_{\Xi_{2}}(t), K_{\Xi_{2}}\left(t, t_{1}\right)$ - математичне очікування і кореляційна функція щодо $\Xi_{2}(t)$.

Якщо випадкова складова вхідного впливу $\Xi_{2}(t) \epsilon$ білим шумом 3 дисперсією $D_{\Xi_{2}}(t)$, тоді $m_{\Xi_{2}}(t)=0, K_{\Xi_{2}}\left(t, t_{1}\right)=D_{\Xi_{2}}(t) \delta_{1}\left(t-t_{1}\right)$ і наведені формули спрощуються

$$
m_{X}(t)=0, K_{X}\left(t, t_{1}\right)=\int_{0}^{t} h(t-\tau) h\left(t_{1}-\tau\right) D_{\Xi_{2}}(\tau) d \tau ; D_{X}(t)=\int_{0}^{t} h^{2}(t-\tau) D_{\Xi_{2}}(\tau) d \tau .
$$

Аналітичні дослідження за наведеними виразами ускладнені через громіздкі кінцеві формули щодо коренів знаменника $Z_{H}(p)$. Істотні спрощення можна отримати при нехтуванні інерційною масою в порівнянні з масою корпусу. Таке припущення цілком прийнятне, зокрема, для вживаних в даний час шахтних геофонів. Якщо $м=0$, тоді замість функцій $h(t)$ и $h_{0}(t)$, зворотне перетворення Лапласа для (7) надає для функцій $h^{0}(t)$ та $h_{0}^{0}(t)$

$$
\begin{aligned}
h^{0}(t)=\frac{1}{\Phi_{0}}\left\{e^{-\lambda t}\left[\Phi_{c} \operatorname{ch}\left(t \sqrt{\lambda^{2}-1}\right)+\Phi_{\lambda s} t \operatorname{shc}\left(t \sqrt{\lambda^{2}-1}\right)\right]-\right. \\
\left.-e^{-\Lambda t}\left[\Phi_{c} \operatorname{ch}\left(t \sqrt{\Lambda^{2}-W_{0}^{2}}\right)+\Phi_{\Lambda s} t \operatorname{shc}\left(t \sqrt{\Lambda^{2}-W_{0}^{2}}\right)\right]\right\} ; \\
h_{0}^{0}(t)=\frac{1}{\Phi_{0}}\left\{e^{-\lambda t}\left[\Psi_{\lambda c} \operatorname{ch}\left(t \sqrt{\lambda^{2}-1}\right)+\Psi_{\lambda s} t \operatorname{shc}\left(t \sqrt{\lambda^{2}-1}\right)\right]+\right. \\
\left.+e^{-\Lambda t}\left[\Psi_{\Lambda c} \operatorname{ch}\left(t \sqrt{\Lambda^{2}-W_{0}^{2}}\right)+\Psi_{\Lambda s} t \operatorname{shc}\left(t \sqrt{\Lambda^{2}-W_{0}^{2}}\right)\right]\right\}
\end{aligned}
$$

де $\Phi_{c}=2\left(\Lambda-W_{0}^{2} \lambda\right) ; \quad \Phi_{0}=W_{1}^{2}+2(\Lambda-\lambda) \Phi_{c} ; \quad \Phi_{\Lambda s}=-\overline{W_{0}}-\Lambda \Phi_{c}$;

$$
\Phi_{\lambda s}=\Phi_{\Lambda s}-(\Lambda-\lambda) \Phi_{c} ; \quad W_{1}=W_{0}^{2}-1 ; \quad \overline{W_{0}}=W_{0}^{2} W_{1} ; \quad \operatorname{shc}(z)\left\{\begin{array}{cc}
\frac{\operatorname{sh}(z)}{z} ; & z \neq 0 \\
1 ; & z=0
\end{array} ;\right.
$$




$$
\begin{aligned}
& \Psi_{\Lambda c}=y_{0}^{\prime} \Phi_{c}-y_{0} \overline{W_{0}} ; \quad \Psi_{\lambda c}=x_{0} \Phi_{0}-\Psi_{\Lambda c} ; \quad \Psi_{\Lambda s}=y_{0}\left(\Phi_{c} W_{0}^{2}+\Lambda \overline{W_{0}}\right)-y_{0}^{\prime} \Phi_{\Lambda s} ; \\
& \Psi_{\lambda s}=\Phi_{0}\left(\lambda x_{0}+x^{\prime}+y_{\mathbf{0}}^{\prime}\right)+y_{\mathbf{0}}^{\prime}\left(\lambda \Phi_{c}+W_{1}\right)+y_{0}\left(\Phi_{0} W_{0}^{2}+\lambda \overline{W_{0}}\right) .
\end{aligned}
$$

Як приклад, наведемо деякі результати обчислень за отриманими співвідношеннями для геофонів, що працюють в дорезонансному режимі, тобто, коли власна частота механічної системи датчика істотно вище максимальної частоти вимірюваних коливань (сигналів). Саме в такому режимі працюють датчики п'єзоелектричного типу, де генерований електричний сигнал є пропорційним до деформації п'єзоелемента. Номінальний частотний діапазон таких датчиків лежить від 0 до 0,3 власної частоти. Найбільше відносне відхилення АЧХ інерційної маси датчика на пружності кріплення п'єзоелемента спостерігається на верхній межі вказаного частотного інтервалу і не перевищує 0,1 . В термінах нашої постановки задачі це відповідає абсолютній жорсткості установки корпусу $\left(W_{0} \rightarrow \infty\right)$, при якій $|X(W)| \in[1 ; 1,1)$, коли $W \in(0 ; 0,3)$. Найбільше відхилення АЧХ від 1 має місце на кінці інтервалу в точці $W=0.3$. Зазвичай власна частота датчика і його ідеалізована АЧХ є основними параметрами під час вибору датчика вимірювальної системи.

Амплітудно-частотні характеристики, що розраховані за (9), наведені на рис. 2 і рис. 3. У загальному випадку криві мають два максимуми при частотах, що несуттєво відрізняються від 1 i $W_{0}$ (від власної частоти інерційної системи датчика і від частоти встановлення корпусу датчика на пружності контакту з породою). Якщо $W_{0}>1$ та $\Lambda_{0}>1$, то АЧХ наближається до виду АЧХ ідеальної одно масової системи акселерометру з яскраво вираженим максимумом при $W=1$. При менших значеннях зазначених параметрів частотна характеристика на інтервалі $(0 ; 0,3) \epsilon$ немонотонною i, отже, зміна умов на контакті з грунтом може привести як до завищення так і до заниження амплітуди зареєстрованих коливань в залежності від початкового стану.

На рис. 4 наведені результати розрахунку за формулами (10) i (12) реакції геофону у вигляді зміщення інерційної маси щодо корпусу геофону на прискорення $\xi^{\prime \prime}(t)$. При цьому використано нормований імпульс Берлаге з одиничним максимумом обвідної у вигляді

$$
B(t, w, n, T)=a^{n} t^{n} e^{-\beta t} \sin (w t) H(t),
$$

де $\beta=\beta(n, T)=\frac{3(1+n)}{T}, \quad a=a(\beta, n)=\left(\frac{\beta e}{n}\right)^{n}, H(t)-$ функція Хевісайда, $T-$ приблизне значення тривалості обвідної.

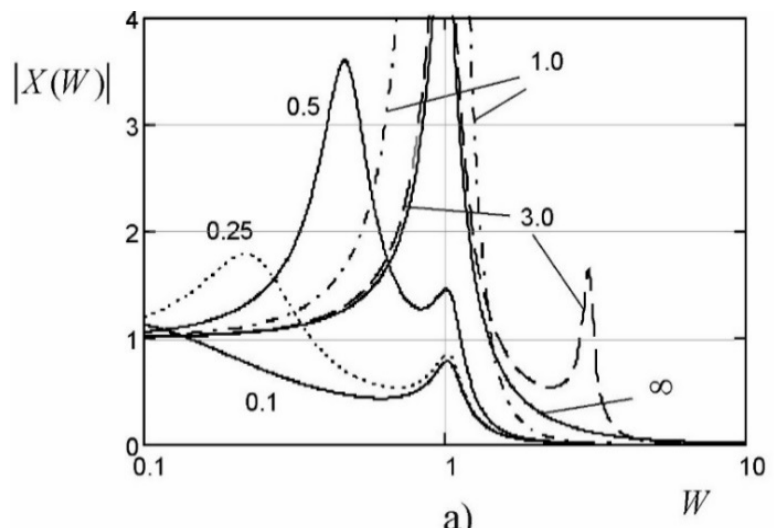

a)

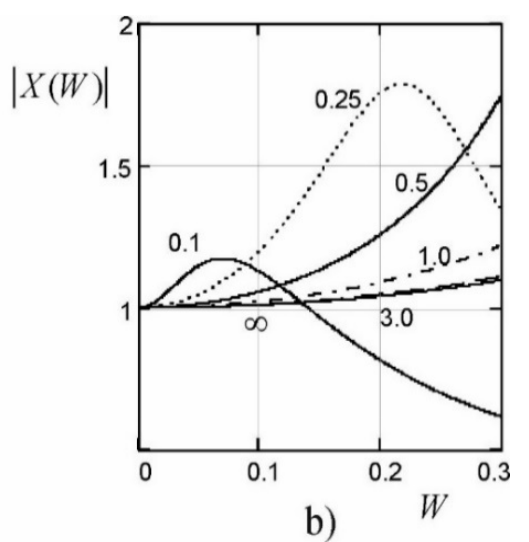

b)

Рис. 2. АЧХ акселерометра при різній жорсткості на контакті з грунтом. Числа у кривих — відповідні значення $W_{0} ; \Lambda=0.1, \lambda=0.1, \mu=0.1$

a) $W \in[0.1 ; 10]$; b) $W \in[0 ; 0.3]$ 

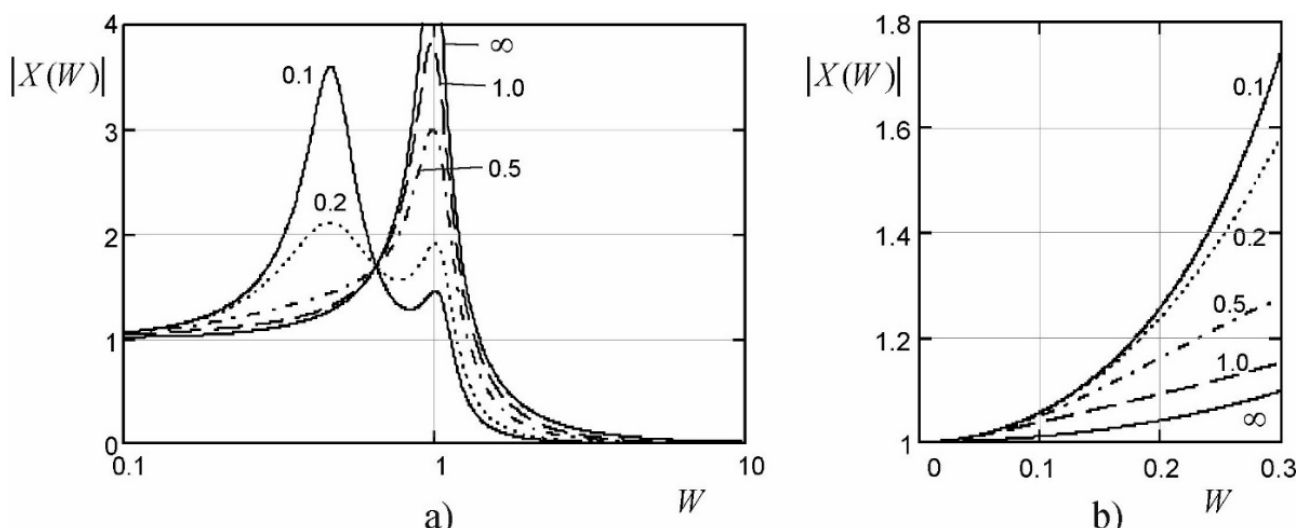

Puc. 3. АЧХ акселерометра при різних коефіцієнтах затухання на контакті з грунтом. Числа у кривих - відповідні значення $\Lambda ; W_{0}=0.5, \lambda=0.1, \mu=0.1$

a) $W \in[0.1 ; 10]$; b) $W \in[0 ; 0.3]$

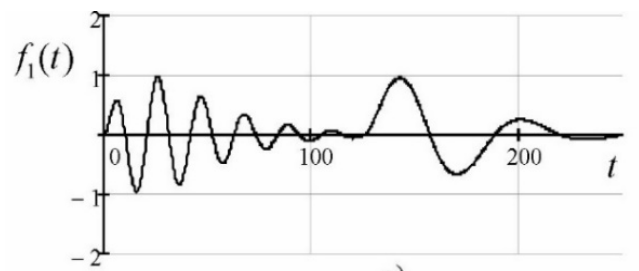

a)

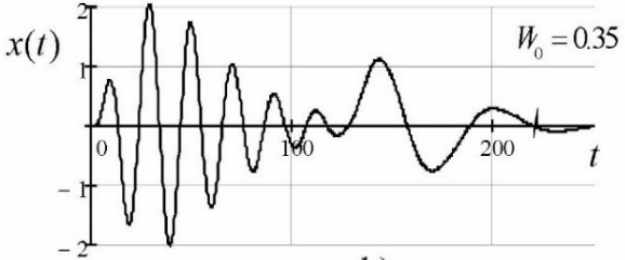

b)

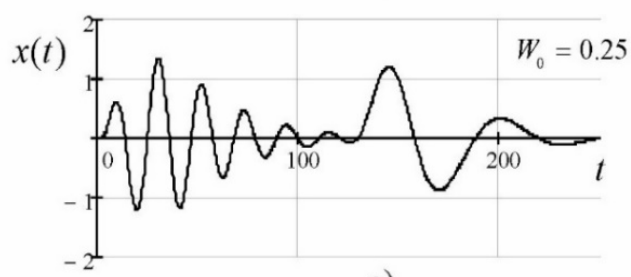

c)

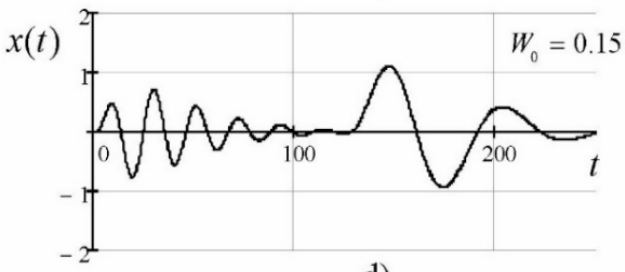

d)

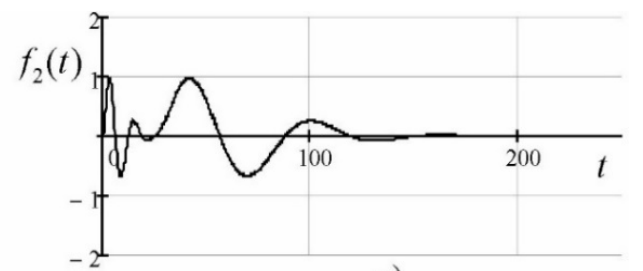

e)

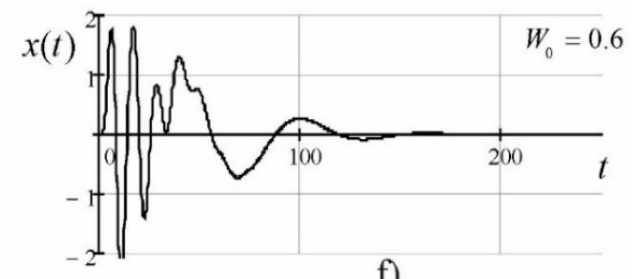

f)

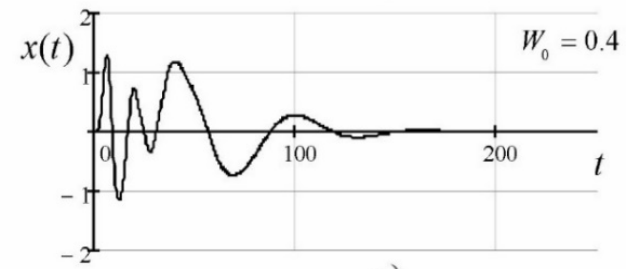

g)

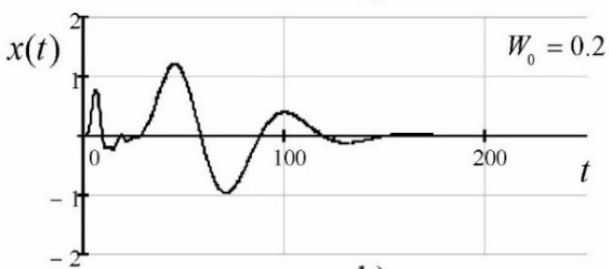

h)

Puc. 4. Реакція інерційної системи сейсмоприймача (b, c, d) i (f, g, h) на вплив у вигляді прискорення задаючої поверхні (а) і (е) відповідно

$\Lambda=0.1, \lambda=0.1, \mu=0.1$

Результати наведені для двох різних функцій $f_{1}(t)$ i $f_{2}(t)$. Кожна з функцій є пара послідовних імпульсів 


$$
f_{i}(t)=B\left(t, w_{i 1}, n_{i 1}, T_{i 1}\right)+B\left(t-T_{i 1}, w_{i 2}, n_{i 2}, T_{i 2}\right), \quad i=1,2 .
$$

Бралися наступні значення параметрів:

$n_{i 1}=n_{i 2}=1, \quad i=1,2 ; \quad w_{11}=0,3 ; \quad w_{12}=0,1 ; \quad T_{11}=T_{12}=40 \pi ;$

$w_{21}=0,5 ; \quad w_{22}=0,1 ; \quad T_{21}=8 \pi ; \quad T_{22}=40 \pi$.

Наведені на рис. 4 криві ілюструють суттєві зміни зареєстрованої характеристики при зміні контактної жорсткості. Цілком зрозуміло, що інтерпретація вимірів тільки по номінальним характеристикам геофону може призводити до суттєвих помилок.

\section{Висновки}

Розглянуто математичну модель механічної системи сейсмоприймача 3 урахуванням контактної взаємодії з грунтом. Отримано кінцеві вирази для обчислення передаточної функції, частотних характеристик і імпульсної перехідної функції. Приклади розрахунків для геофонів дорезонансного типу можна розглядати як первинну оцінку впливу властивостей грунту на реєстровані параметри. Подальші уточнення моделі, вочевидь, вимагатимуть застосування наближених обчислень. При цьому результати даної роботи можуть бути використані для верифікації розрахунків.

\section{Список використаної літератури}

1. Гамбурцев Г.А. Основы сейсморазведки. Москва: Гостоптехиздат, 1959. 378 с.

2. Аверко Е.М., Нефёдкин Ю.А. Сейсмоприёмник - почва (обзор). Инериионные источники и приёмники сейсмических волн. Сборник научных трудов. Новосибирск, 1972. С. 132-144. URL: https://www.geokniga.org/bookfiles/geokniga-inercionnye-istochniki-i-priemnikiseysmicheskih-voln.pdf (дата звернення 22.04.21)

3. Анциферов М.С. Теория геофонов и виброметров звукового диапазона. Москва: Наука, 1976. $144 \mathrm{c}$.

4. Гликман А.Г. Спектральная сейсморазведка - истоки и следствия. [e-book]. URL: https://newgeophys.spb.ru/ru/book2/1-1.shtml (дата звернення 20.04.21)

5. Segarra P., Sanchidriбn J.A., Castedo R., del Castillo I. Coupling of blasting seismographs to rock and its effectiveness for horizontal ground motion. International Journal of Rock Mechanics and Mining Sciences. 2017. Vol. 92, P. 81-90.

6. Kann F., Winterflood J. Simple method for absolute calibration of geophones, seismometers, and other inertial vibration sensors. Review of Scientific Instruments. 2005. Vol. 76, No. 3. https://doi.org/10.1063/1.1867432

7. Krohn, C. E. Geophone ground coupling. Geophysics, 1984. Vol. 49. No. 6, P. 722-731.

8. Wang Y., Fu N., Fu Z., Lu X., Liao X., Wang H., Qin S. Semi-Automatic Coupling Geophone for Tunnel Seismic Detection. Sensors (Basel), 2019. Vol. 19. No. 17. https://doi.org/10.3390/s19173734

9. Wei Z., Hall M. A. Analyses of vibrator and geophone behavior on hard and soft ground. The Leading Edge, 2011. Vol. 30. No. 2. P. 132-137.

https://dx.doi:10.1190/1.3555320

10.Крылов В.И., Скобля Н.С. Методы приближённого преобразования Фурье и обращения преобразования Лапласа. Москва: Наука, 1974. 224 с. 


\title{
MATHEMATICAL MODEL OF MECHANICAL SYSTEM OF SEISMOACOUSTIC OSCILLATION RECEIVER \\ Golovko Yu.
}

\begin{abstract}
A seismic receiver (geophone) is a necessary element of a seismoacoustic measuring system. The main function of the mechanical subsystem of the seismic receiver is the transformation of ground oscillations into the kinematic characteristics of the inertial mass of the device relatively to the housing. Experiments show that the measurement results significantly depend on the physical and mechanical properties of the soil. Mathematical modeling of the geophone is allowed to estimate the impact of soil properties on the recorded signals for the true interpretation of the measurement results.

A linear model of the geophone is considered with the ground contact. External effect on the installed geophone is set in the form of a known function of the ground motion relative to the inertial reference system. The problem is reduced to a system of two ordinary linear differential equations. Laplace transformation was used. The resulting image solution makes it possible to obtain the transfer and frequency functions. After performing the inverse transformation, the transition function is obtained. The solution with arbitrary initial conditions is presented in an analytical form. The possibility of using the obtained dependences is shown on the example of a pre-resonant type geophone. The influence of changes in the contact stiffness and viscosity on the amplitude spectrum and shape of seismograms is considered.
\end{abstract}

Taking into account the need for further complication of the model, the obtained solution can be used to verify the approximate calculations.

\section{References}

[1] Gamburtsev, G. A. (1959) Osnovy seysmorazvedki. Moskva: Gostoptekhizdat, 378.

[2] Averko, Ye. M., Nefodkin, Yu. A. (1972) Seysmopriyomnik - pochva (obzor). Inertsionnyye istochniki i priyomniki seysmicheskikh voln. Sbornik nauchnykh trudov. Novosibirsk, 132 144. Retrieved from URL:https://www.geokniga.org/bookfiles/geokniga-inercionnye-istochnikii-priemniki-seysmicheskih-voln.pdf.

[3] Antsiferov, M. S. (1976) Teoriya geofonov i vibrometrov zvukovogo diapazona. Moskva: Nauka, 144.

[4] Glikman, A. G. Spektral'naya seysmorazvedka - istoki i sledstviya. [e-book]. URL: https://newgeophys.spb.ru/ru/book2/1-1.shtml.

[5] Segarra P., Sanchidrion J.A., Castedo R., del Castillo I. Coupling of blasting seismographs to rock and its effectiveness for horizontal ground motion. International Journal of Rock Mechanics and Mining Sciences. 2017. Vol. 92, P. 81-90.

[6] Kann F., Winterflood J. Simple method for absolute calibration of geophones, seismometers, and other inertial vibration sensors. Review of Scientific Instruments. 2005. Vol. 76, No. 3. https://doi.org/10.1063/1.1867432.

[7] Krohn, C. E. Geophone ground coupling. Geophysics, 1984. Vol. 49. No. 6, P. 722-731.

[8] Wang Y., Fu N., Fu Z., Lu X., Liao X., Wang H., Qin S. Semi-Automatic Coupling Geophone for Tunnel Seismic Detection. Sensors (Basel), 2019. Vol. 19. No. 17. https://doi.org/10.3390/s19173734.

[9] Wei Z., Hall M. A. Analyses of vibrator and geophone behavior on hard and soft ground. The Leading Edge, 2011. Vol. 30. No. 2. P. 132-137. https://dx.doi:10.1190/1.3555320.

[10] Krylov, V. I., Skoblya, N.S. (1974) Metody priblizhonnogo preobrazovaniya Fur'ye i obrashcheniya preobrazovaniya Laplasa. Moskva: Nauka, 224. 